\title{
Desenvolvimento profissional docente: reflexões a partir de trajetórias de professores de Física
}

Teacher professional development: thoughts based on the trajectories of Physics teachers

\author{
Wilson Elmer Nascimento ${ }^{1}$ \\ Elisabeth Barolli²
}

\section{Resumo}

Dada a importância de se compreender os condicionantes contextuais que podem influenciar o desenvolvimento profissional docente, este trabalho investigou as trajetórias de três professores de Física. A partir de entrevistas semiestruturadas, organizamos o campo de análise, reconstruindo as trajetórias dos professores, articulando os aspectos que compuseram suas aprendizagens em diferentes contextos. Nossos resultados evidenciaram o desenvolvimento profissional desses professores em diversas dimensões, tais como: atualização nos conhecimentos científicos e pedagógicos, organização e condução do ensino, sustentação da aprendizagem dos alunos, investigação da própria prática e planejamento da carreira profissional. Concluímos que a análise de trajetórias docentes se torna mais efetiva por oferecer uma visão mais pormenorizada e orgânica sobre a formação de professores, expressando, assim, a importância e necessidade do professor vivenciar uma diversidade de contextos para sua formação contínua.

Palavras chave: desenvolvimento profissional docente; trajetórias; contextos; ensino de física.

\section{Abstract}

Given the relevance of comprehending the conditioning constraints that can influence teacher professional development, this work has investigated the trajectories of three Physics teachers. Based on semi-structured interviews, we have organized the field of analysis, reconstructing the teachers' trajectories, articulating the aspects that composed their learning in different contexts. Our results highlighted the professional development of these teachers in several dimensions, such as: update in their scientific and pedagogical knowledge, organizing and conducting teaching, supporting students' learning, investigating their practice, and planning their professional careers. We conclude that the analysis of teaching trajectories becomes more effective because it offers a more detailed and organic view on teacher training, expressing thus the importance and need for teachers to experience a diversity of contexts for their continuous training.

Keywords: teacher professional development; trajectories. contexts; Physics teaching.

\footnotetext{
${ }^{1}$ Universidade Federal do Rio Grande do Norte | wilson-elmer@hotmail.com

${ }^{2}$ Universidade Estadual de Campinas | bethbarolli@gmail.com
} 


\section{Introdução}

Nas últimas décadas, tem crescido consideravelmente o número de pesquisadores que se debruçam acerca da problemática do desenvolvimento profissional docente (DAY, 2001; VILLEGAS-REIMERS, 2003; ÁVALOS, 2007; MARCELO, 2009; GOMES; FIORENTINI; GONÇALVES, 2014; VAILLANT, 2016; BAROLLI et al., 2019). Essas pesquisas têm colocado em discussão as condições contextuais propícias para o desenvolvimento profissional, inclusive na perspectiva de desenvolver estratégias que possam favorecer a formação contínua dos professores das mais diversas áreas, incluindo a área de Ensino de Ciências e de Matemática.

O próprio termo "desenvolvimento" remete a uma ideia de evolução e continuidade, o que para Marcelo (2009) é o que supera a tradicional aproximação entre formação continuada e aperfeiçoamento dos professores. Ao se adotar o conceito de desenvolvimento profissional docente, tem-se como pressuposto, uma abordagem formativa que leva em conta seus aspectos contextuais, organizacionais e que sejam orientados para a transformação do professor ao longo do tempo (MARCELO, 2009).

Mizukami (2013) ao ressaltar a complexidade do trabalho do professor, manifesta uma concepção de desenvolvimento profissional docente estruturada como um processo que ocorre de maneira lenta ao longo da vida do sujeito. Coaduna-se com essa perspectiva Fiorentini (2008) quando ressalta que o desenvolvimento profissional do professor é um processo contínuo que tem início antes mesmo do sujeito ingressar na licenciatura, passando por toda sua vida profissional, ocorrendo em diversos espaços e momentos de sua vida.

Os processos de desenvolvimento profissional dos professores podem, por um lado, guardar muitas semelhanças entre si; por outro lado, serem muito diferentes em diversos contextos. Podem até mesmo possuir uma variedade de dimensões e abordagens dentro de um mesmo contexto. Assim, entendemos que não há uma forma ou modelo de desenvolvimento profissional mais eficaz do que o outro, sendo essa eficácia muito dependente das condições contextuais em que esse modelo se aplica (VILLEGAS-REIMERS, 2003; MARCELO, 2009; VILLANI; BAROLLI; NASCIMENTO, 2020).

Mesmo em uma mesma escola, diferentes fatores contextuais, relacionados sobretudo à estrutura e à cultura escolar, podem influenciar a maneira pela qual o professor se implica num movimento de transformação de suas práticas, nomeadamente, na forma como o professor se desenvolve profissionalmente. Os professores, como indivíduos ou como coletivo, devem avaliar as suas necessidades, crenças e práticas culturais, a fim de decidir quais abordagens de desenvolvimento profissional serão mais adequadas para suas situações particulares.

Além disso, o desenvolvimento profissional docente "ocorre ao longo do tempo, e não em momentos isolados, e que o aprendizado ativo requer oportunidades de conectar conhecimentos anteriores aos novos" (COCHRAN-SMITH-LYTLE, 1999, p. 7).

Como exposto, compactuamos com uma concepção de desenvolvimento profissional docente que para se realizar requer uma série de características, processos, métodos e contextos, que vão se articulando ao longo do tempo. Parece-nos, portanto, oportuno investigar trajetórias docentes na perspectiva de compreender as condições que professores buscam ou encontram para se desenvolver profissionalmente (VILLANI; BAROLLI; NASCIMENTO, 2020). Nessa perspectiva, focalizamos neste trabalho as trajetórias de três professores/as de Física que se encontram na docência por mais de duas décadas. A análise 
desses percursos reforça a importância e a necessidade de uma formação continuada com uma diversidade de contextos que dialoguem com questões que efetivamente venham a subsidiar a prática docente.

\section{Dimensões do desenvolvimento profissional de professores de Ciências}

Nossa compreensão sobre a complexidade da profissão docente, aliada às contribuições de diversos autores educacionais, nos leva a considerar que uma epistemologia que fundamente o desenvolvimento profissional se define por meio da interlocução do professor com diversas instâncias que interferem na atividade docente. Nesse sentido, concordamos com Barolli e colaboradores (2019), que elaboraram um ferramental com o intuito de instrumentalizar a análise de processos de desenvolvimento profissional docente, mais especificamente no contexto do ensino de Ciências.

Esses autores fundamentaram uma concepção de desenvolvimento profissional como um processo no qual as aprendizagens ao longo do tempo se efetivam pelo diálogo com três diferentes interlocutores: a academia, a escola e a sociedade. Em outras palavras, contextos formativos que se propõem a criar condições para que o professor se desenvolva profissionalmente seriam mais efetivos ao proporcionar oportunidades para a implicação com os saberes próprios da produção acadêmica, com as diferentes questões e atores que caracterizam os contextos escolares e ainda, com as particularidades da função social da escola e do ofício do magistério. Esses diálogos, no que Ihes concernem, serviram de subsídio para estabelecer um esquema de análise com o potencial de caracterizar o desenvolvimento profissional de professores de Ciências por meio de um conjunto de dimensões (BAROLLI et al., 2019). Ao passo em que os professores se desenvolvessem no âmbito dessas dimensões, entre outros aspectos que caracterizam o desenvolvimento do professor enquanto profissional, seriam contemplados os diferentes conhecimentos, saberes e competências próprios da profissão docente (SHULMAN, 1987; COCHRAN-SMITH; LYTLE, 1999; PERRENOUD, 2000; DAY, 2001; TARDIF, 2002; VILLEGAS-REIMERS, 2003; MARCELO, 2009).

O diálogo com a academia, ou seja, com centros formadores de professores e de produção científica, representa a possibilidade de o professor ampliar e aprofundar seus saberes de natureza científica e pedagógica, por meio de cursos de extensão, cursos de especialização ou de pós-graduação, de parcerias entre universidade e escola, projetos institucionais etc. É por meio dessa interlocução que o professor encontra a oportunidade de se desenvolver profissionalmente, em especial, em duas dimensões: atualização nos conhecimentos científicos e atualização nos conhecimentos pedagógicos (BAROLLI et al., 2019).

Considerando que aprendizagens como essas, invariavelmente, impactam de maneira significativa as formas pelas quais os professores conduzem suas práticas pedagógicas, esses docentes podem também desenvolver-se em duas outras dimensões: organização e condução do ensino e sustentação da aprendizagem dos alunos. $O$ desenvolvimento dos professores de Ciências nessas duas últimas dimensões também pode ser alcançado no âmbito de processos colaborativos realizados no contexto escolar, ou seja, por meio do diálogo do professor com a escola. Esse diálogo com a escola pode também reverberar em 
outra dimensão, qual seja, participação na gestão escolar, na medida em que a instituição escolar representa um espaço de troca de experiências e de organização das atividades promovidas pelos colegas professores, coordenadores e diretores da escola (BAROLLI et al., 2019).

Nessa concepção de desenvolvimento profissional, para o professor que se encontra em exercício, os diálogos com a escola e com a academia criariam condições favoráveis para a inquirição da própria prática na medida em que se configuram como instâncias privilegiadas de interlocução permitindo um processo de constante revisão e reflexão da prática. É nesse sentido que essa integração pode criar condições catalisadoras para o desenvolvimento em outra dimensão, definida como investigação da própria prática. Considera-se ainda o fato de que o processo de desenvolvimento profissional também está articulado ao diálogo com a Sociedade. Isto é, essa interlocução representa o posicionamento do professor, bem como sua escuta, frente às iniciativas promovidas pelos agentes educacionais e cíveis, e pelas instituições que promovem a justiça social. É nesse sentido que o professor pode se desenvolver na dimensão participação na responsabilidade social. Transversal a esses diálogos, os autores definem, ainda, uma última dimensão, denominada planejamento da carreira profissional. Essa dimensão ocupa um papel importante no esquema de análise, uma vez que consiste no estabelecimento, por parte do professor, de uma agenda de metas profissionais e de estratégias para alcançá-las (BAROLLI et al., 2019).

A proposição dessas dimensões fundamentadas com base nos diálogos com os interlocutores representa, por um lado, uma forma de tornar ainda mais evidente a complexidade do ofício docente e, por outro, uma tentativa de contribuir para o campo da formação de professores de modo a perscrutá-lo a partir de determinado ponto de vista. Ao mesmo tempo em que essas dimensões são amplas, elas tentam sintetizar âmbitos da carreira dos professores que podem ser aperfeiçoados e desenvolvidos ao longo do tempo.

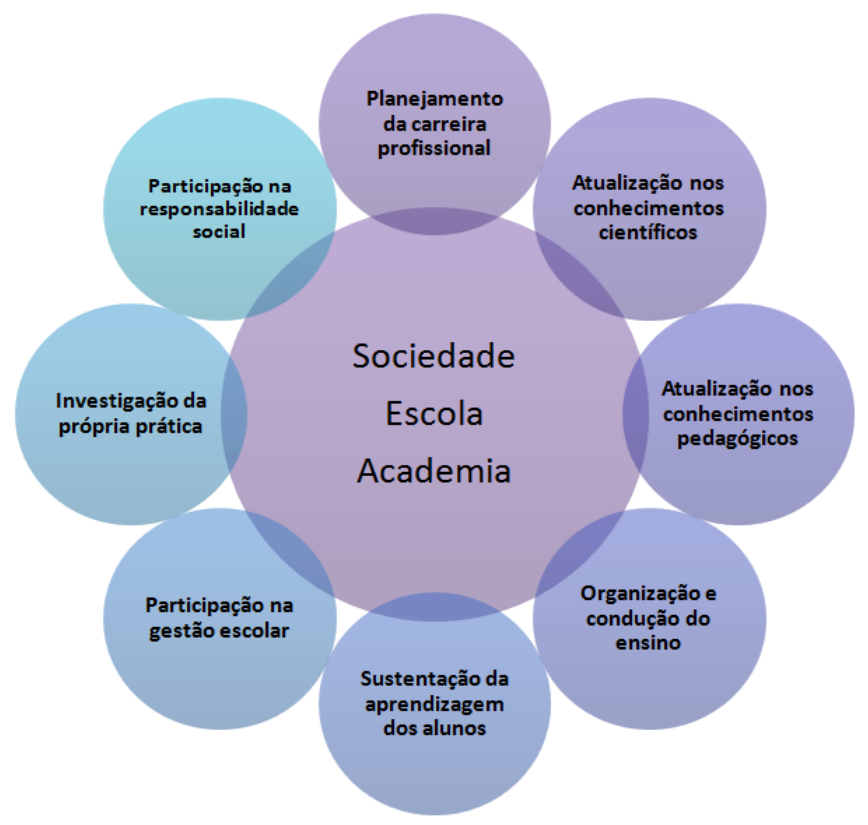

Figura 1: Dimensões do desenvolvimento profissional de professores de Ciências. Fonte: Baseado em (BAROLLI et al., 2019) 
É oportuno salientar que essas oito dimensões admitem imbricações, pois determinadas ações que um professor realiza em determinados contextos podem ser interpretadas como uma superposição entre duas ou mais dimensões. Por exemplo, um professor que participe constantemente de reuniões de planejamento didático junto com outros professores no contexto de um grupo colaborativo, mas que tem implicações institucionais na escola, pode resultar num desenvolvimento profissional nas dimensões atualização nos conhecimentos pedagógicos e participação na gestão escolar.

\section{Considerações metodológicas}

A perspectiva metodológica desta investigação segue os preceitos da abordagem qualitativa. Todo o percurso metodológico - o processo de escolha, coleta e análise dos dados - foi orientado pelas abordagens interpretativas, privilegiando a compreensão dos fenômenos sociais a partir de um contato profundo com os sujeitos investigados (DENZIN; LINCOLN, 2006).

Nosso objetivo com esta investigação foi investigar trajetórias de professores que permaneceram na carreira, no sentido de compreender os condicionantes contextuais que influenciaram seus desenvolvimentos profissionais e, em consequência, suas práticas. A opção por focalizar as trajetórias docentes em contraposição a eventos isolados que, eventualmente, marcaram essas percursos deve-se ao fato de entendermos que, desse modo, é possível alcançar uma visão mais pormenorizada e orgânica sobre como os professores foram se desenvolvendo profissionalmente e com isso sugerir aspectos que podem ser fundamentais para a formação docente.

Para atender a este objetivo, de modo a explicitar processos de desenvolvimento profissional docente, realizamos um conjunto de entrevistas semiestruturadas com professores/as de Física. Participaram das entrevistas três professores/as de Física do ensino básico, aqui denominados/as: Nanda, Nuno e Olívia. Em média cada professor/a concedeu cerca de quatro horas de entrevistas, divididas em duas ou três sessões, em períodos diferentes, em função de suas disponibilidades.

Em cada sessão foram focalizados diferentes aspectos, sendo a primeira direcionada à trajetória formativa e profissional, a segunda à trajetória pessoal e a terceira, quando necessária, se prestou a elucidar e aprofundar alguns aspectos discutidos nas duas outras sessões anteriores. Todas as entrevistas foram gravadas em áudio, sendo em seguida transcritas, constituindo a base para o material empírico da presente investigação.

Para organizar o campo de análise reconstruímos as trajetórias profissionais dos/as professores/as articulando aspectos que compuseram suas vivências em diferentes contextos. Como considera Vandenberg (2016, p. 101), contextos são como "uma espécie de conceito guarda-chuva, no entanto, abarcam tudo com que os atores se deparam no seu ambiente e que impingem sobre suas ações no presente e a partir do exterior (classe, organizações, instituições etc.)".

Por meio da reconstrução dessas trajetórias foi possível identificar a maneira pela qual os/as professores/as foram alcançando ao longo do tempo aprendizagens que thes permitiram desenvolver-se profissionalmente, tendo como referência o instrumento apresentado anteriormente, baseado nas oito dimensões do desenvolvimento profissional de professores de Ciências (BAROLLI et al., 2019). 


\section{Caracterização dos professores}

Nanda tinha 33 anos na época das entrevistas. Era solteira, residia com sua mãe e irmã em uma grande cidade brasileira e atuava como professora de Física em uma tradicional instituição federal de ensino. Possui formação superior em Letras - Espanhol, bacharelado e licenciatura em Física. Inicialmente atuou como professora de espanhol na rede municipal de ensino. Anos mais tarde passou a lecionar Física no contexto de uma escola pública vinculada à universidade. No que se refere aos estudos pós-graduados, Nanda formou-se mestre em Ensino de Física (Mestrado Profissional - MP) e doutora em Ensino de Ciências, ambos os títulos alcançados em universidades públicas. Além disso, participou de inúmeras formações complementares, com destaque para a Escola de Física em Língua Portuguesa do CERN (Organização Europeia para a Pesquisa Nuclear), onde pôde aprofundar seus conhecimentos em Física Moderna e Contemporânea.

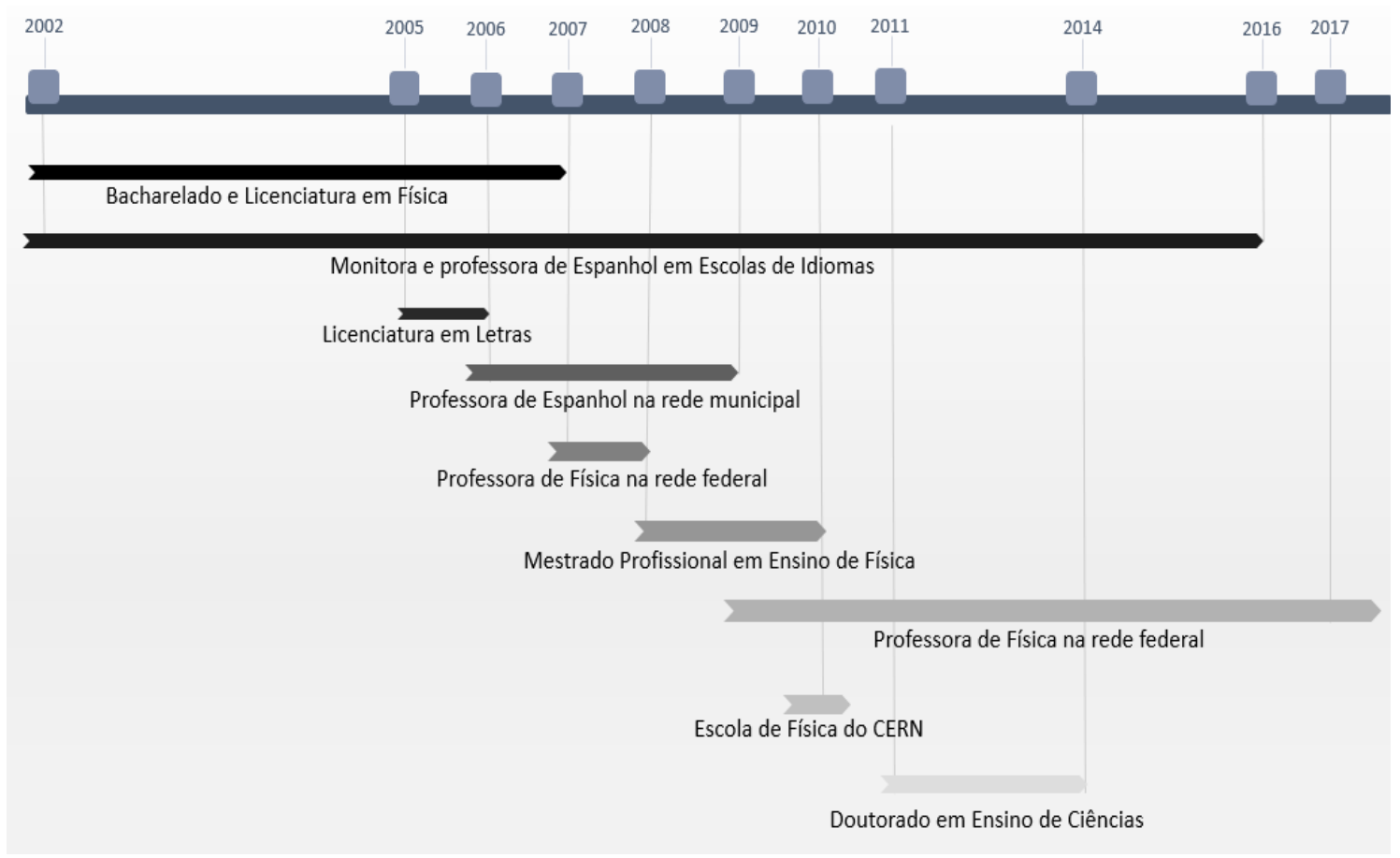

Figura 2: Contextos formativos e profissionais de Nanda.

Nuno tinha 56 anos de idade, morava em uma grande cidade brasileira, tinha quatro filhos e era casado. Na época das entrevistas, já aposentado, era professor de laboratório de Física em uma escola privada muito tradicional e conceituada da cidade. Nuno passou quase três décadas como oficial das Forças Armadas (FA), contexto em que também atuou como professor de Física. Por muitos anos foi professor particular de Física, Química e Matemática e em cursos preparatórios. Cursou licenciatura curta em Ciências na década de 1980 e licenciatura plena em Física cerca de 20 anos depois. Além disso, formou-se mestre em Ensino de Física em um curso de Mestrado Profissional (MP). Além de atuar como professor de Física no contexto das FA, atuou em escolas particulares e, voluntariamente, na coordenação de inúmeros projetos na área de Astronomia. 


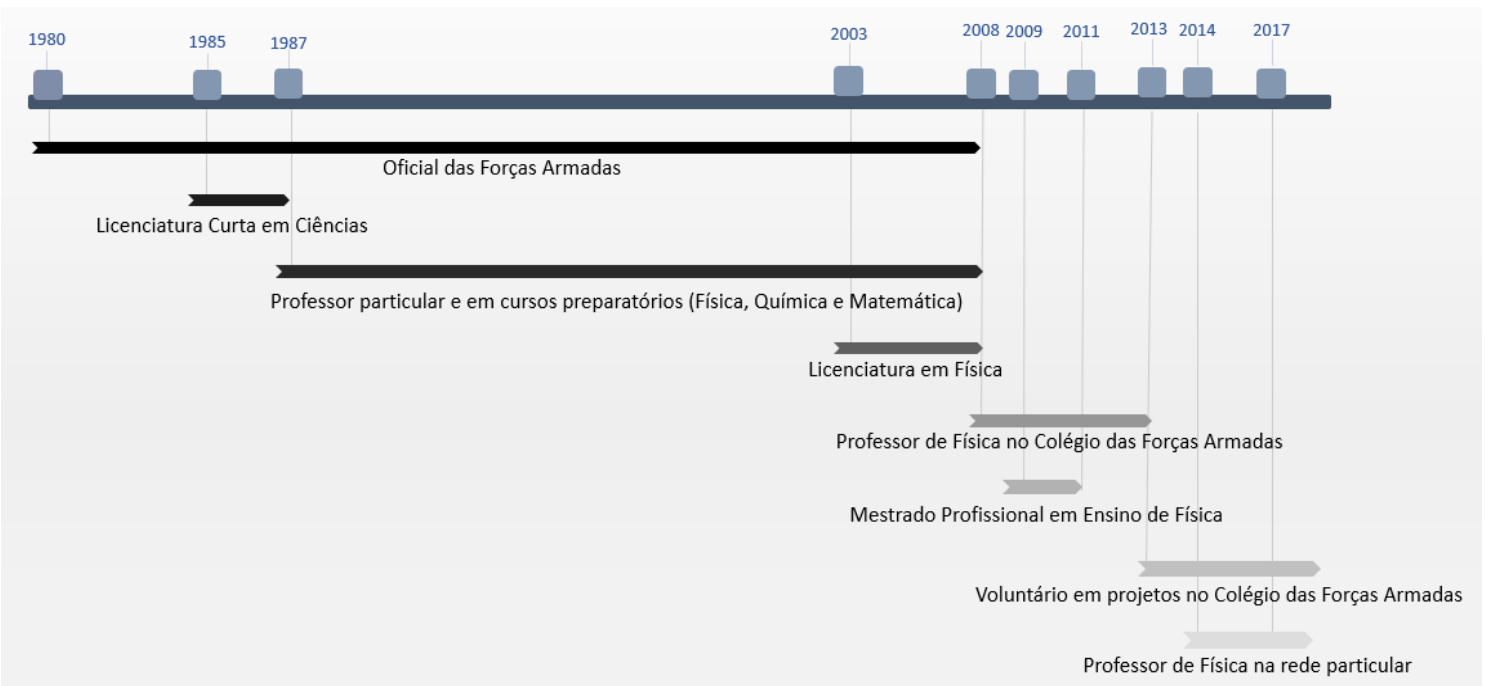

Figura 3: Contextos formativos e profissionais de Nuno.

Na época das entrevistas Olívia tinha 59 anos e morava sozinha em uma grande cidade brasileira. Mãe de um filho e separada há muitos anos, era professora de Física da rede municipal de ensino. Formou-se em licenciatura em Física em uma universidade privada na década de 1980. Ao longo dos anos, atuou no magistério em diversas instituições de ensino, tais como de escolas particulares, escolas públicas estaduais e municipais, cursinhos prévestibulares, cooperativas e no ensino público superior. Realizou uma especialização em Psicologia da Educação na modalidade à distância e titulou-se mestre em Ensino de Física em um curso de Mestrado Profissional (MP). Na época das entrevistas encontrava-se cursando uma segunda graduação, em Astrofísica, também por uma universidade pública.

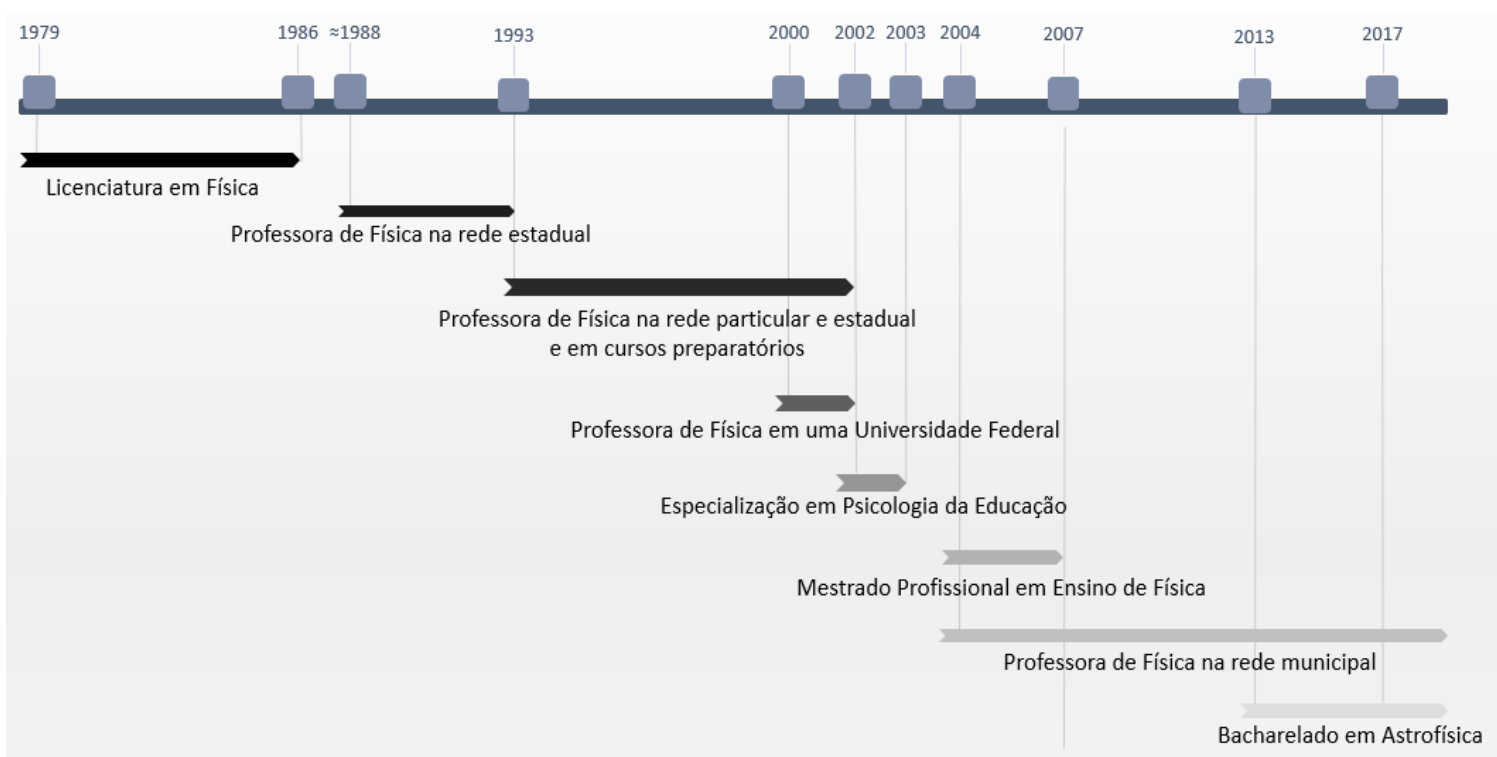

Figura 4: Contextos formativos e profissionais de Olívia.

\section{Resultados e discussão}

O campo das pesquisas na área de formação de professores tem revelado que é possível alcançar um ganho significativo na análise do desenvolvimento profissional por meio da reconstrução das trajetórias de professores que têm se mantido na carreira sem 
renunciar à meta de favorecer a aprendizagem. Essas análises possibilitam um olhar diacrônico para as histórias dos professores e, ao mesmo tempo, atento aos condicionantes contextuais que mobilizam ou limitam as aprendizagens docentes.

Há que se considerar que os contextos formativos pelos quais os/as professores/as sujeitos desta pesquisa passaram, tinham como perspectiva o desenvolvimento profissional docente. Apesar dessas características, como afirmam Villani, Barolli e Nascimento (2020) a maneira como cada sujeito explora esses contextos é, em geral, diferenciada.

No caso da professora Nanda, sua trajetória revela um incessante investimento na aprendizagem, o que a levou a um percurso acadêmico e profissional de elevado sucesso e com níveis de aproveitamento altíssimos. Todos os contextos formativos pelos quais passou, em concomitância com suas práticas profissionais nas escolas em que atuou, foram imprescindíveis em sua atualização nos conhecimentos científicos.

Especificamente, no que corresponde aos conhecimentos de Física, o MP, o doutorado e a Escola de Física no CERN foram preponderantes para o aprofundamento em temáticas específicas da área em que atua. No desenvolvimento de seu produto educacional, a relação de proximidade com o orientador especialista em Física Térmica proporcionou a Nanda um aprimoramento e domínio desse conteúdo da Física. "[...] a minha monografia foi sobre dilatação térmica, meu mestrado [também] foi sobre dilatação térmica e outras coisas e o meu doutorado também foi com física térmica, [sempre com] esse professor" (NANDA, 2017). Por sua vez, a empreitada no CERN permitiu que Nanda entrasse em contato com o que havia de mais tecnológico e atual no que se refere a física contemporânea. Os cursos realizados nesse período e os posteriores estudos para o desenvolvimento de projetos favoreceram muitas aprendizagens sobre a Física de Partículas, bem como suas formas de ensinar. "[...] tinha a possibilidade de me aproximar de um conteúdo de Física mais avançado para eu me apropriar, mas sempre pensando em como levá-lo para os alunos" (NANDA, 2017).

Também em Nuno, verificamos uma transversalidade em sua maneira de se relacionar com o conhecimento e em seu desenvolvimento nessa dimensão. Os contextos mais profícuos para atualização nos conhecimentos científicos foram, em escala crescente de aprendizagem, os cursos e trabalhos realizados nas FA, a licenciatura curta em Ciências, a licenciatura plena em Física e o MP. Na pós-graduação Nuno pôde aprofundar-se nos conhecimentos de física por meio de algumas disciplinas específicas.

O que eu aprendi na licenciatura plena e no mestrado, tanto na questão dos conceitos da física, do formalismo matemático e das questões do ensino de física, mudou completamente a forma como eu vejo o ensino de física em relação ao tempo em que eu ficava mais com os cursinhos e com o EJA. [...] O que também ajudou muito a compreender o fio condutor para se trabalhar as questões da ciência e da física foi a disciplina de História da Ciência. Foram disciplinas que se destacaram pela novidade que nos causou. Trabalhar assuntos da física, "física dura", com um pouco mais de profundidade, lógico que não é a profundidade de um mestrado acadêmico (NUNO, 2015).

Para Olívia, a proximidade com a academia por meio do MP e posteriormente do curso de graduação em Astrofísica reverberou substancialmente em sua prática em sala de aula. Sua atualização nos conhecimentos científicos ocorreu principalmente no MP e em sua segunda graduação. No primeiro pôde revisitar e aprofundar áreas da física com as quais 
não tinha contato há muito tempo, como por exemplo Mecânica Quântica: "[...] porque eu já estava afastada há muito tempo e não lembrava de mais nada" (OLÍVIA, 2015). Olívia também recordou que no período do MP teve a oportunidade de, por meio de uma disciplina, aprender de forma mais significativa como os processos de construção dos conhecimentos em física se deram ao longo da história.

[...] a parte de história da física também, com o professor [docente do MP], foi muito interessante, de como é que as coisas chegaram aqui, então isso eu pude aprender essa linha toda né, de como é que a física foi se desenvolvendo (OLÍVIA, 2015).

Os cursos de MP se constituíram como os contextos mais ricos no que concerne a atualização nos conhecimentos pedagógicos. Para Nanda, foi fundamental para suprir o que ela considerava uma grande lacuna de sua licenciatura. A professora reconheceu que, em algumas disciplinas especializadas em Ensino de Física, pôde se aprofundar em conceitos oriundos das Ciências da Educação, bem como em aspectos relacionados à prática propriamente dita.

[...] por mais que eu faça todos os exercícios do livro eu acho que só com isso não vou conseguir chegar ao meu aluno com isso apenas. Preciso de mais. Não de mais conteúdo, mas de mais mecanismos, de mais elementos para elaborar como vou ensinar determinada coisa (NANDA, 2015).

A professora, em toda sua formação, mostrou-se bastante atenta às oportunidades de se aprofundar em conhecimentos pedagógicos, principalmente por meio de estudos acadêmicos realizados após a graduação, como o MP e o doutorado.

No caso de Nuno, foi possível perceber que o professor aproveitou todas as condições oferecidas pelo contexto da licenciatura plena em Física e do MP para que incorporasse em seu repertório pedagógico uma gama de novos conhecimentos acerca das teorias de aprendizagem e do currículo.

E a questão do mestrado profissional para quem é professor contribui muito, principalmente sobre teorias de aprendizagem. Nos dá um embasamento, uma condição de se trabalhar educação, não usando aquilo que está na minha cabeça, mas sim usando a teoria de alguém que fez uma pesquisa, que fez um trabalho, isso é muito importante (NUNO, 2015).

Nuno pôde valer-se desses conhecimentos em seu trabalho na escola, sobretudo quando precisava se posicionar diante de críticas vindas de alguns pais de alunos.

Já fui questionado por pais que diziam: "O senhor está dando aula de jeito errado! O senhor tem que escrever no quadro e os alunos copiam". Eu deixei o cidadão falar bastante e disse: "Agradeço as suas sugestões, mas qual é o teórico de aprendizagem que fundamenta essa sua metodologia?" Disse ainda: "Eu não dou aula da minha cabeça; quando eu preparo uma aula eu levo em consideração duas teorias de aprendizagem, a de Vigotsky e Ausubel". [...] Quando eu estou montando uma aula, eu estou constantemente pensando em Vigotsky e em Ausubel, interação social, zona de desenvolvimento proximal, aprendizagem significativa, conhecimentos prévios (NUNO, 2016). 
De modo geral, Olívia percebeu um avanço em relação ao que praticava antes do curso de MP, início do período de intensa interlocução com a universidade. Na dimensão atualização nos conhecimentos pedagógicos atingiu outro patamar de desenvolvimento a partir do MP, onde, por meio das disciplinas e da elaboração da dissertação e do produto educacional, pôde aprofundar-se em conhecimentos curriculares na produção e análise de livros didáticos, na elaboração de recursos e materiais instrucionais e nos conhecimentos de teorias de aprendizagem. Essas vivências proporcionaram a Olívia certa expertise para assumir com mais propriedade as escolhas dos livros didáticos em sua escola, propondo inclusive, no âmbito de suas aulas, modificações pontuais nos conteúdos que seriam priorizados.

Era um modo de trabalhar e vamos embora. [...] Eu trabalhava com apostilas nas escolas. Eu reproduzia aquilo e pronto, enganava um pouco. [...] Então hoje, como o governo federal manda livros didáticos para as escolas, hoje eu tenho condições de examinar um livro didático e ver o que é bom e o que não é. [...] O livro do primeiro ano tem um enfoque sobre energia muito interessante, muito legal (OLÍVIA, 2015).

Ainda com relação a Olívia, e também no caso de Nanda, as condições contextuais dos cursos de MP, sobretudo no que se refere às disciplinas que abordavam conteúdos pedagógicos, constituíram-se como dinamizadores para o desenvolvimento profissional nas dimensões organização e condução do ensino e sustentação da aprendizagem dos alunos. Os elementos apontados pelas professoras nos indicam que os cursos de MP em que participaram se constituíram como divisores de águas no que se refere a forma de ensinar física, pois passaram a considerar em sua prática aquilo que os alunos já sabem, rompendo, inclusive com a rigidez na condução das aulas.

Nas nossas aulas se discutia que tínhamos que deixar o aluno falar, colocar propostas, atividades em que o aluno considere que está contribuindo. Esses eram discursos que surgiam durante o mestrado, apontando que os nossos alunos possuem ideias prévias que não podem ser desconsideradas. [...] Eu aprendi muito mais e tenho certeza de que minhas aulas são muito melhores por conta disso [...] (NANDA, 2015).

Por que que os alunos não aprendiam? Esse foi o meu maior questionamento. E a conclusão que eu cheguei é de que eu estava muito engessada, a física estava muito engessada, muito ligada a matemática, em vez de conceitos físicos. Isso foi uma coisa que eu aprendi aqui [MP], eu aprendi novas tecnologias que podia usar. [...] Os ganhos que eu tive na minha vida profissional são enormes, hoje eu sou outra profissional [...]. Hoje eu já não aceito mais ficar engessada dentro de uma apostila. Hoje eu viajo aqui, para lá, puxo coisas. Hoje eu tenho coragem de afrontar esse roteiro, parar com essa rigidez (OLÍVIA, 2015).

Nanda reconheceu que os momentos em que as práticas dos professores cursistas eram colocadas como objetos de análise e reflexão, eram frutíferos para todos. Considerou, ainda que o diálogo com a academia oportunizava a constituição de um grupo colaborativo, mesmo que de forma pontual.

A gente interagia bastante e era uma troca bacana, porque a gente via as experiências que cada um trazia da sala de aula. [...] Os meus colegas 
davam relatos de experiências em relação ao conhecimento específico e de como isso ajudava para elaborar a aula e as atividades. Eles também faziam relatos sobre questões de ensino. Às vezes alguém me abordava dizendo que eu estava fazendo tudo errado e eu tentava ponderar, porque cada um tem mais facilidade em algum aspecto. Então eu acho que essas disciplinas, principalmente as de ensino, foram muito importantes porque muitas coisas eram discutidas, muitas coisas foram faladas (NANDA, 2015).

Além disso, a passagem de Nanda pela Escola de Aplicação também contribuiu para seu desenvolvimento profissional nas dimensões organização e condução do ensino e sustentação da aprendizagem dos alunos. Ou seja, ela pôde aproveitar de saberes experienciais, isto é, aqueles que são gerados pelos professores na atividade cotidiana de sala de aula (TARDIF, 2002). Segundo ela, foi nesse contexto que aprendeu a ser professora de Física: "[...] foi onde de fato eu aprendi a dar aula de física na escola" (NANDA, 2017); e iniciou um contínuo processo de reflexão da própria prática mediatizada pela interlocução com seus colegas de trabalho.

[...] se eu estou aqui hoje foi porque eu passei pela Escola de Aplicação, foi pelo que aprendi vendo meus colegas professores de física trabalhando. [...] Eu queria absorver aquelas pessoas porque elas tinham muito para me ensinar, daquele fazer, daquela escola, daquelas coisas (NANDA, 2017).

Para Olívia, o desenvolvimento profissional nessas dimensões foi fundamental para superar as principais dificuldades em sala de aula, sobretudo aquelas concernentes à aprendizagem e à falta de estrutura física das escolas em que lecionava. "Eu sempre faço alguma experiência em aula. Principalmente demonstrações porque a gente nunca tem laboratório" (OLÍVIA, 2016). Muito identificada com a escola pública, atuar em escolas municipais era um privilégio para Olívia, pois considerava que possuía muito mais autonomia em sala de aula. "Se eu quero ensinar um conceito de Física, eu tenho liberdade de fazer isso de várias maneiras e eu escolho a maneira que seja mais adequada a eles, a vivência deles, ao que eles têm hoje em dia" (OLíVIA, 2015).

No caso de Nuno, as estratégias de organização e condução do ensino, bem como os mecanismos de sustentação da aprendizagem dos alunos foram totalmente reelaborados por meio de sua vivência junto a universidade em articulação com sua prática pedagógica em sala de aula.

Antes eu me preocupava em dar a resposta, hoje eu me preocupo em fazer a pergunta. Que pergunta que eu vou fazer para ele para que ele se sinta motivado e desafiado? É uma mudança de perspectiva muito interessante. Hoje o aluno chega e eu não dou o resultado, não. Eu reluto e reluto para que ele descubra o que precisa descobrir (NUNO, 2017).

Principalmente a partir de sua entrada na licenciatura plena em Física, Nuno passou a se implicar num processo que Day (2001) chama de explorar o continuum, isto é, passou a ampliar sua visão sobre quais aspectos da aprendizagem docente poderia investir.

E nesses 31 anos eu fui pegando uma maneira de perceber que aquilo que você aprende na sala de aula, como os objetos do conhecimento que você vai trabalhar com aluno [conteúdo específicos] é secundário. Então 
quer dizer que não precisa saber física? Claro que precisa, mas muito mais você precisa ser humano, você precisa ser uma pessoa que goste de pessoas. Para entender isso, você precisa entrar em sala de aula (NUNO, 2017).

Engajado nesse processo, Nuno prolongou seu diálogo com a Academia durante o MP com ênfase na interlocução com o campo da investigação das práticas de ensino de física. A articulação entre seu trabalho de sala de aula e os conhecimentos produzidos no âmbito acadêmico, sistematizados e colocados como objetos de análise e reflexão denota, mesmo que pontual e circunscrito ao contexto do MP, o desenvolvimento profissional de Nuno na dimensão investigação da própria prática.

Ele dizia [docente do MP]: "o que é que esse mestrado vai mudar no professor que chegou aqui e o professor que saiu daqui?. E essa frase ficou na minha cabeça e cada vez mais eu buscava ligar aqueles problemas de sala de aula, conceitos físicos, problemas de aprendizado, com o que eu aprendia no mestrado e como poderia me ajudar a mudar dentro do trabalho em sala de aula (NUNO, 2015).

A aproximação de Nuno com a Universidade por meio da licenciatura em Física e do MP se constituiu como contexto para que ele problematizasse e revisasse seus métodos de trabalho.

[...] na minha percepção o fato de estar na sala de aula e estar fazendo o mestrado de maneira concomitante foi fundamental para que eu tivesse, na minha perspectiva, um sucesso muito grande, depois que eu saí do mestrado. Sucesso em que sentido? Em trabalhar melhor as questões do ensino, em entender melhor as lacunas cognitivas dos alunos, em ter um norte de onde trabalhar as questões da aprendizagem (NUNO, 2015).

Assim como para Nuno, Nanda e Olívia também se desenvolveram nessa dimensão após a interlocução com a Academia por meio do MP e posteriormente durante o doutorado no caso de Nanda e nas parcerias com docentes da universidade no caso de Olívia.

Nanda ingressou no MP com o intuito de, por meio da aproximação com a área de Ensino de Física, refletir sobre sua prática de ensino. Seu anseio inicial foi alcançado em parte naquele contexto e em parte em outros contextos formativos, como por exemplo o doutorado. Nanda passou por experiências profissionais muito promissoras no que se refere ao desenvolvimento da dimensão investigação da própria prática, sobretudo ao trabalhar com professores mais experientes que se dispunham a ajudá-la em uma perspectiva colaborativa. "A minha reflexão tem que ser contínua. A todo momento a gente tem que dar sentido para o trabalho" (NANDA, 2017).

Olívia, por sua vez, possuía uma grande inquietação em relação às dificuldades de aprendizagem em Física dos estudantes e essa problemática era o grande motor para a inquirição de sua própria prática, que pôde ser aperfeiçoada por meio da diversificação das formas de ensinar (desenvolvimento nas dimensões organização e condução do ensino e sustentação da aprendizagem dos alunos). Na ocasião de uma das entrevistas, quando relatava que constantemente estava refletindo sobre sua prática docente, Olívia mostrou ao entrevistador uma série de atividades que vinha desenvolvendo com seus estudantes do 
ensino médio. "Eu proponho desafio, vou construindo as coisas. Esse é o meu rascunho, é uma solução que eu inventei" (OLÍVIA, 2016).

Na medida em que os professores investigam e geram conhecimento local teorizando sobre a própria prática, pode-se concluir que esse movimento se constitui como elemento essencial para o desenvolvimento profissional docente, assim como um meio para o desenvolvimento das instituições escolares nas quais esses professores estão inseridos (COCHRAN-SMITH; LYTLE, 2009).

Ficou patente na análise das trajetórias dos/as três professores/as de Física o estabelecimento de metas profissionais e de estratagemas para alcançá-las. Nesse sentido, podemos admitir que esses/as professores/as também se desenvolveram na dimensão planejamento da carreira profissional. O percurso profissional de Nanda foi marcado por um rigoroso planejamento e investimento profissional, fazendo com que alcançasse grandes empreendimentos no âmbito da carreira do magistério. O que se nota é que cada passo dado por Nanda foi cuidadosamente planejado, seja ao buscar por cursos de formação (licenciaturas, MP, CERN, doutorado) ou por suas escolhas profissionais (rede municipal e federal), sempre com a perspectiva de ascensão na carreira e, principalmente, satisfação pessoal.

Eu tenho uma trajetória acadêmica que eu me privei de muitas coisas para ser graduada, por isso que eu valorizo muito minhas graduações, às vezes até mais que o mestrado e o doutorado. Foi um momento de muitas renúncias na minha vida, pois fui direto do Ensino Médio, era jovem. Não me arrependo desse caminho, mas foi um caminho de muito estudo, de ter muitas aulas, de estudar muito em casa, de trabalhar ao longo do processo todo. [...] eu fui para o mestrado com a ideia de que se eu melhorasse a minha prática eu seria uma professora melhor. [...] Por entender como a ciência se constrói, eu decidi que eu queria fazer parte disso também, e só com mestrado talvez não seria o caso. Eu tive a ideia de fazer o doutorado, eu tive incentivo dos meus professores, porque eu tirava boas notas e era interessada (NANDA, 2017).

Nuno sempre buscou aperfeiçoar-se profissionalmente, sobretudo quando passou a dedicar-se integralmente à profissão docente. Embora sua longa trajetória dentro das FA já tenha Ihe trazido um certo nível de consolidação da carreira, foi buscar um aprofundamento de seu desenvolvimento profissional no MP em Ensino de Física. O que se nota é uma busca de ascensão que não tinha nenhuma motivação financeira, haja vista que o título de mestre não afetava seu salário, mas sim, um progresso de reconhecimento dentro da escola das FA, que contava com muitos professores mestres e doutores. "Na academia, o mestre vale muito. $\mathrm{Na}$ [escola das FA] eu tive que construir meu relacionamento com os professores. $\mathrm{O}$ corpo docente de lá é top" (NUNO, 2016).

A nosso ver, na ocasião das entrevistas, o professor Nuno encontrava-se no momento mais fértil e intenso de sua trajetória profissional no magistério: "Eu trabalho de segunda a sexta na escola particular, às vezes à noite tem Projeto de astronomia, sábado e domingo às vezes tem algum congresso ou alguma palestra" (NUNO, 2016). Muito próximo de completar 60 anos de idade, Nuno ainda pensava em fazer um doutorado, seja como continuidade do projeto que realizou no MP ou um doutorado específico em Ensino de Astronomia. 
Eu tenho uma frase que é assim: "a palavra convence, mas o exemplo arrasta". O exemplo de você estar junto, de você trabalhar, de você estudar e de você nunca parar de estudar, de você sempre estar aprendendo. Quando eu estou em casa eu estou lendo um livro de Física, uma Astronomy, mostrando algum documentário sobre Física, falando alguma coisa desse tipo. [...] As revistas da Astronomy estão sempre comigo. [...] Eu considero uma perda de tempo, quando se está sem fazer "nada", não está lendo. (NUNO, 2016).

Ao focalizarmos a trajetória docente de Olívia, também notamos que a professora se encontrava no momento mais fecundo de seu desenvolvimento profissional, haja vista que se sentia bastante satisfeita com seu contexto de trabalho e constantemente se implicava em processos de reflexão e de ação para aprimorar esse contexto, assim como vinha fazendo por meio da interlocução com a universidade. Seu desenvolvimento na dimensão planejamento da carreira profissional se deu principalmente por seu investimento contínuo em cursos, como a especialização e o MP. "Aqui no Município eu fiquei em primeiro lugar no concurso porque eu tinha o título de mestre. Dois títulos: de especialista e de mestre" (OLÍVIA, 2016). Assim, os cursos de pós graduação foram fundamentais para ela, pois com essas titulações conseguiu ter acesso a contextos de trabalho que ela própria considerava privilegiados. Esse desenvolvimento também se denota em seu investimento em outra graduação (Astrofísica), algo que acima de tudo lhe trouxe muita satisfação pessoal.

Em síntese, a explicitação das trajetórias dos/as professores/as que fizeram parte da pesquisa, embora apresentada de forma resumida, deixa transparecer, em todos os casos, uma busca constante por sentirem-se satisfeitos com o exercício da profissão. "Eu acho que só vou parar de dar aula no dia que eu não tiver mais condições físicas e só paro de aprender quando o cansaço não deixar mais" (NUNO, 2017). E essa satisfação se sustenta, sobremaneira, em participar de contextos que Ihes deem oportunidade de se desenvolverem profissionalmente em diferentes dimensões. Os elementos por nós destacados a partir de seus depoimentos puderam ser interpretados de acordo com seis dimensões do desenvolvimento profissional de professores de Ciências (BAROLLI et al., 2019), embora haja particularidades no processo percorrido por eles/as.

\section{Considerações finais}

Embora haja especificidades nas trajetórias dos/as três professores/as, há que se destacar que todas elas têm em comum o fato de que todos/as alcançaram uma integração pessoal ao participarem e vivenciarem contextos formativos de diversas naturezas. No que se refere à graduação todos os/as professores/as cursaram a licenciatura plena em Física, como também outra graduação (licenciatura curta em Ciências, Letras - Espanhol e Astrofísica).

Além disso, outros contextos também foram marcantes no que se refere a possibilidade do/a professor/a agregar saberes que vieram a contribuir significativamente para a melhoria de seus conhecimentos de base, sobretudo no âmbito da prática propriamente dita. Contextos de natureza mais acadêmica, como o MP e o doutorado, tiveram influência decisiva na atualização dos conhecimentos científicos e pedagógicos. A Escola do CERN, em particular, embora não tenha o mesmo status de um curso de pós-graduação, ofereceu à professora Nanda, o ensejo de introduzir a Física Moderna em sua prática pedagógica. 
Os/as professores/as tiveram a oportunidade e autonomia de praticar a profissão, atuando em diferentes contextos escolares, tais como em diferentes redes e níveis de ensino. A atuação desses/as professores/as em diferentes contextos escolares thes trouxe a oportunidade de articular as aprendizagens alcançadas no diálogo com a Academia. Desse modo, puderam exercitar práticas inovadoras de ensino por meio de estratégias e metodologias diversificadas, implementar estratégias didáticas problematizadoras que levassem em consideração as ideias prévias dos alunos, flexibilizar o planejamento e a condução das aulas, sustentar a prática com base na epistemologia da aprendizagem, entre outros.

O que se nota, portanto, é que essa variedade de condições contextuais, forneceu elementos para que esses/as professores/as tivessem possibilidade de se desenvolver profissionalmente em diversas dimensões. Nesse sentido, esse desenvolvimento profissional parece ter sido, nestes casos, consequência da diversidade, bem como do aproveitamento dos potenciais de quatro contextos de naturezas distintas, a saber: formação inicial (licenciatura em Física), pós-graduação (MP e doutorado), formação em serviço (prática profissional nas escolas) e cursos de atualização ou outras licenciaturas.

Os resultados deste trabalho nos permitem refletir sobre o fato de que a profissão docente requer sobremaneira a complementação contínua da formação. O professor Nuno, em particular, revela que sua trajetória foi marcada pela Licenciatura Plena em Física pelo fato deste curso lhe ter dado condições de renovar suas rotinas e inovar sua prática. Para o professor que só havia cursado a licenciatura curta, "ensinar Física era ensinar os guris a resolver os problemas de Física" (NUNO, 2015). Com a licenciatura plena, percebeu que "não é nada disso, ensinar Física é outra coisa, a Física é o guri entender os conceitos" (NUNO, 2015).

A nosso ver o desenvolvimento profissional contínuo, diacrônico e contextual é fundamental para que o professor alcance saberes múltiplos e competências adequadas para alcançar o nível de profissionalização requerido para atuar em um mundo cada vez mais exigente e dinâmico. Como vimos, em acordo com nosso referencial, os/as professores/as mantiveram diálogo constante tanto com a escola, quanto com a academia. No entanto, pelo menos por ocasião das entrevistas, não temos indícios sobre a maneira pela qual se efetiva o diálogo dos/as professores/as com a Sociedade, em relação a suas participações em ações de cunho moral, político e social, bem como na implementação de ações orientadas pelos princípios de igualdade, equidade, justiça e democracia. Em outras palavras, esse diálogo tem ressonância com um dos modelos docentes, cunhado por Contreras (2002), denominado Intelectual Crítico. O autor aponta que o intelectual crítico deve ter a capacidade de não só promover, desenvolver e solucionar os problemas decorrentes do ensino a partir de uma ação com sentido moral, mas também desenvolver junto com os estudantes as "bases para a crítica e a transformação das práticas sociais que se constituem ao redor da escola" (CONTRERAS, 2002, p. 158).

Parece-nos que para o professor estabelecer um diálogo com a sociedade é necessário que ele assuma seu papel de intelectual crítico, de forma a ter condições de avaliar com propriedade o sentido político e social de sua profissão, e sustentar o compromisso com a transformação de sua prática. Para tanto, o diálogo com as outras instâncias teriam uma função importante no sentido de problematizar "os valores ideológicos dominantes, as práticas culturais e as formas de organização [que] podem não só limitar as possibilidades 
de ação do professor, mas também as próprias perspectivas de análise e compreensão do ensino, de suas finalidades educativas e de sua função social" (CONTRERAS, 2002, p. 185).

As considerações desenvolvidas anteriormente sugerem não só a complexidade dos processos de desenvolvimento profissional, mas também a importância dos cuidados a se tomar no desenho de contextos que têm como finalidade a formação continuada, ou mais especificamente o desenvolvimento profissional docente. Sugerem, ainda, que esses contextos criem condições para que o professor possa se implicar com os saberes próprios da academia, com as diferentes questões que atravessam a escola e as diversas atividades escolares, bem como com as questões que caracterizam o ofício do magistério no âmbito da sociedade, reconhecendo a escola como um equipamento social.

\section{Referências}

BAROLLI, E.; NASCIMENTO, W. E.; MAIA, J. O.; VILLANI, A. Desarrollo professional de professores de ciências: dimensiones de análisis. Revista Electrónica de Enseñanza de las Ciencias. v. 18, n. 01, p. 173-197, 2019. Disponível em: http://reec.uvigo.es/volumenes/volumen18/REEC_18_1_9_ex1369.pdf. Acesso em: 24 fev. 2020.

ÁVALOS, B. El desarrollo profesional continúo de los docentes: lo que nos dice la experiencia internacional y de la región latinoamericana. Revista Pensamiento Educativo, $v$. 41, n. 2, p. 77-99, 2007.

COCHRAN-SMITH, M.; LYTLE, S. L. Relationships of Knowledge and Practice: teacher learning in communities. Review of Research in Education, v. 24, p. 249-305, 1999.

COCHRAN-SMITH, M.; LYTLE, S. L. Inquiry as Stance: Practitioner Research for the Next Generation. New York: Teachers College Press, 2009.

CONTRERAS, J. A autonomia de professores. São Paulo: Cortez, 2002.

DAY, C. Desenvolvimento Profissional de Professores: os desafios da aprendizagem permanente. Porto: Porto Editora, 2001.

DENZIN, N. K.; LINCOLN, Y. S. O Planejamento da Pesquisa Qualitativa: teorias e abordagens. 2. ed. Tradução: Sandra Regina Netz. Porto Alegre: Artmed, 2006. 432 p.

GOMES, E. B.; FIORENTINI, D.; GONÇALVES, T. O. Bases teórico-epistemológicas do desenvolvimento profissional docente em uma perspectiva catastrófica (DPDPC). Amazônia:

Revista de Educação em Ciências e Matemáticas, v. 11, n. 21, p. 53-69, 2014.

FIORENTINI, D. A pesquisa e as práticas de formação de professores de Matemática em face das políticas públicas no Brasil. Bolema, n. 29, p. 43-70, 2008.

MARCELO, C. Desenvolvimento Profissional Docente: passado e futuro. Sísifo - Revista de Ciências da Educação, n. 8, p. 7-22, 2009.

MIZUKAMI, M. G. N. Escola e desenvolvimento profissional da docência. In: GATTI, B. A.; SILVA JÚNIOR, C. A.; PAGOTTO, M. D. S.; NICOLETTI, M. G. Por uma política nacional de formação de professores. São Paulo: Editora Unesp, 2013, p. 23-54.

NANDA. Entrevista. Rio de Janeiro (Rio de Janeiro), 10 maio. 2015. 
NANDA. Entrevista. São Carlos (São Paulo), 25 janeiro. 2017.

NUNO. Entrevista. Porto Alegre (Rio Grande do Sul), 17 novembro. 2016.

NUNO. Entrevista. Porto Alegre (Rio Grande do Sul), 18 abril. 2015.

NUNO. Entrevista. Porto Alegre (Rio Grande do Sul), 5 outubro. 2017.

OLíVIA. Entrevista. Porto Alegre (Rio Grande do Sul), 16 novembro. 2016.

OLÍVIA. Entrevista. Porto Alegre (Rio Grande do Sul), 20 maio. 2015.

PERRENOUD, P. Dez novas competências para ensinar. Porto Alegre: Artes Médicas Sul, 2000.

SHULMAN, L. S. Knowledge and teaching: foundations of the new reform. Harvard Educational Review, v. 57, n. 1, p. 1-22, 1987.

TARDIF, M. Saberes docentes e formação profissional. Petropólis: Vozes, 2002.

VAILLANT, D. El fortalecimiento del desarrollo profesional docente: una mirada desde Latinoamérica. Journal of Supranational Policies of Education (JoSPoE). v. 5, n. 2, p. 5-21, 2016.

VANDENBERGHE, F. A sociologia na escala individual: Margaret Archer e Bernard Lahire. In: VANDENBERGHE, F.; VERAN, J. (Org.). Além do habitus: teoria social pós-bourdieusiana. 1. ed. Rio de Janeiro: 7 Letras, 2016, p. 95-126.

VILLANI, A.; BAROLLI, E.; NASCIMENTO, W. E. Revisitando trajetórias docents: uma sinergia entre contextos e disposições. Investigações em Ensino de Ciências, v. 25, n. 3, p. 270-299, 2020.

VILLEGAS-REIMERS, E. Teacher professional development: an international review of the literature. Paris: International Institute for Educational Planning, 2003. 